\title{
Erratum to: Xenophobia and Tolerance Toward Immigrants in Adolescence: Cross-Influence Processes Within Friendships
}

\author{
Maarten Herman Walter van Zalk • Margaret Kerr • \\ Nejra van Zalk • Håkan Stattin
}

Published online: 7 April 2013

(C) Springer Science+Business Media New York 2013

\section{Erratum to: J Abnorm Child Psychol \\ DOI 10.1007/s10802-012-9694-8}

The original version of the article was published with error in the spelling of given name of the second author. Magraret should have been spelled as Margaret as shown above.

The online version of the original article can be found at http://dx.doi.org/ 10.1007/s10802-012-9694-8.

M. H. W. van Zalk $(\varangle) \cdot$ M. Kerr $\cdot$ N. van Zalk $\cdot$ H. Stattin

Center for Developmental Research, Örebro University,

Fakultetsgatan 21,

70183 Örebro, Sweden

e-mail: Maarten.vanzalk@oru.se

M. Kerr

e-mail: Margaret.kerr@gmail.com

N. van Zalk

e-mail: nejra.van-zalk@oru.se

H. Stattin

e-mail: hakan.stattin@oru.se

M. H. W. van Zalk

Youth and Society (YeS), Center for Developmental Research, JPS: Psychology, Örebro University,

70182 Örebro, Sweden

M. H. W. van Zalk

Research Centre Adolescent Development, Utrecht University, P.O. Box 80.140, 70182 Utrecht, TC, the Netherlands 